\title{
INDUSTRIAL APPLICATION OF HYBRID LASER-ARC WELDING (Review)
}

\author{
I.V. KRIVTSUN ${ }^{1,2}$, V.Yu. KHASKIN ${ }^{2}$, V.N. KORZHIK ${ }^{1,2}$ and LUO ZIYI ${ }^{1}$ \\ ${ }^{1}$ Guangdong General Research Institute for Industrial Technologies \\ (Guanzhou Research Institute of Non-Ferrous Metals) \\ Guangzhou, PRC \\ ${ }^{2}$ E.O. Paton Electric Welding Institute, NASU \\ 11 Bozhenko Str., 03680, Kiev, Ukraine. E-mail: office@paton.kiev.ua
}

\begin{abstract}
Welding technology improvement is the prerequisite for progress of industrial production. Development of new structures often requires application of high-efficient welding processes, which ensure minimizing the residual deformations. Unfortunately, capabilities of the traditional arc technologies do not always meet such requirements. Laser welding technologies are not always acceptable, either, in view of the high equipment cost and requirements to preparation of items to be welded. Over the recent years hybrid laser-arc welding technologies, combining the advantages of arc and laser processes, have become ever wider accepted. Therefore, this work is a review of modern tendencies in development of hybrid laser-MIG welding of metals and alloys. It is shown that alongside continuation of research, such tendencies include industrial application (for instance, in different sectors of transportation, chemical, power and food industry) oriented towards partial replacement of laser and arc welding technologies. Examples of such applications are given. Development of new technologies of hybrid welding, focused on joining structures differing by their composition and geometry, as well as designing new production equipment for realization of these technologies is noted. Under the conditions of a new stage in laser equipment development, which began in the last decade, and which is associated with a broad industrial introduction of fibre and disc lasers, the issue of selection of laser or hybrid welding has become the subject of scientific-technical and economic analysis. 37 Ref., 5 Figures.
\end{abstract}

Keywords: hybrid laser-MIG welding, welding heads, process parameters, mode selection, development history, industrial application

Welding technology improvement is a prerequisite for progress of industrial production. Creation of new structures often requires application of high-efficient welding processes, which ensure minimizing the residual deformations. Unfortunately, the possibilities of traditional arc technologies do not always meet such requirements. Laser welding technologies are not always acceptable, either, in view of the high cost of equipment and requirements to preparation of items to be welded. Over the recent years, hybrid laser-arc welding technologies, combining the advantages of arc and laser processes, have been ever wider accepted. This study is devoted to tendencies in their development.

As was shown by Steen et al. in their works $[1,2]$, combining laser radiation with electric arc allows development of new welding technologies, offering considerable technological advantages, compared to laser welding (Figure 1) [3]. These advantages include, primarily, deep penetration, low level of residual stresses and lower requirements to fit-up of the edges to be welded.

(c) I.V. KRIVTSUN, V.Yu. KHASKIN, V.N. KORZHIK and LUO ZIYI, 2015
Heating of metal being welded by the electric arc increases the coefficient of laser radiation absorption, that leads to lowering of laser energy losses and allows welding speed to be increased. The same effect is manifested in increase of cross-

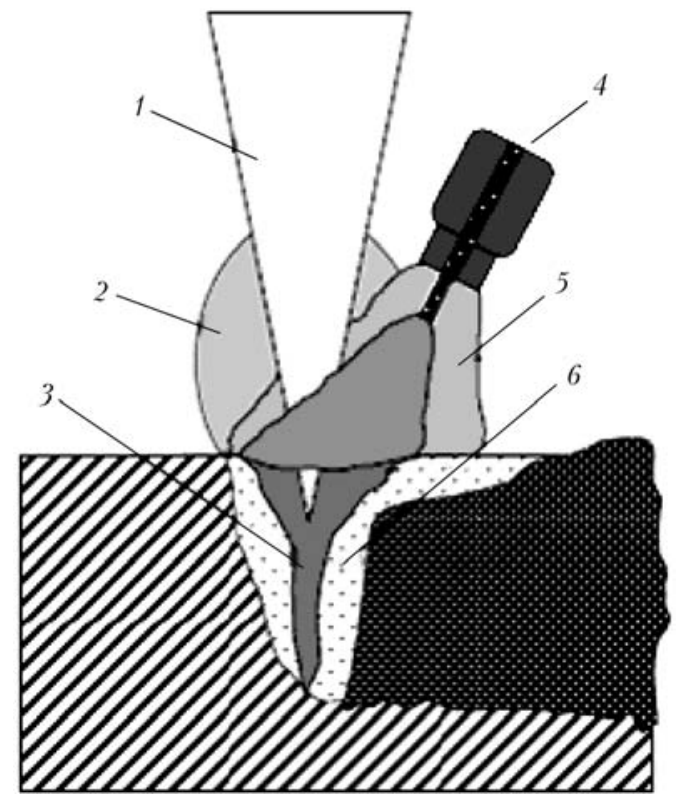

Figure 1. Schematic of hybrid laser-MIG welding [3]: 1 laser radiation; 2 - laser plasma; 3 - vapour-gas channel; 4 - consumable electrode arc; 5 - shielding gas; $6-$ weld pool 

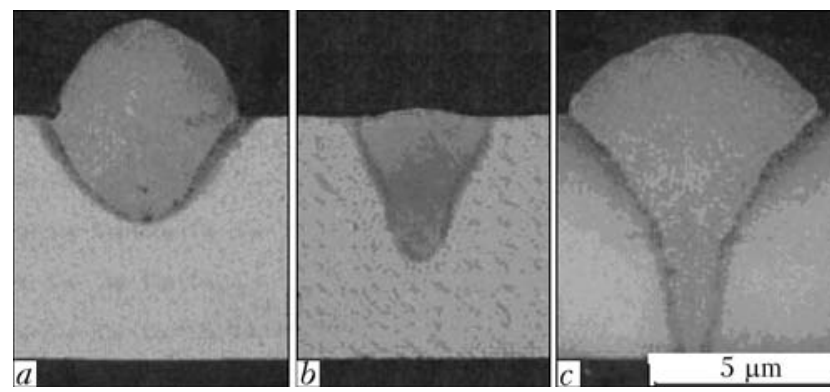

Figure 2. Cross-sections of penetrations made in mediumcarbon steel plate by arc $(a)$, laser $(b)$ and hybrid $(c)$ processes (in hybrid welding distance between wire and focused beam $D_{\mathrm{LA}}=2 \mathrm{~mm}$, wire extension of $11 \mathrm{~mm}$, arc torch inclination of $60^{\circ}$ ) [4]: $a-$ cross-sectional area of $20.31 ; b-7.30 ; c-30.08 \mathrm{~mm}^{2}$

sectional area of metal remelted in hybrid welding, compared to the sum of cross-sectional areas of beads produced by arc and laser welding separately (Figure 2) [4]. In its turn, electric arc is constricted to the dimensions of welded metal vapour plume, formed under the impact of laser radiation, and complements the effect from laser radiation impact. Therefore, hybrid laser-MIG welding requires smaller power lasers, compared to laser welding, that makes the process less costly. Modification of thermal cycle of laser welding, occurring under the arc impact, improves weld structure $[2,5]$.

The torch for modern hybrid welding can be both a simple combination of laser welding head with arc torch (Figure 3), and a complex integrated device (Figure 4). Such torches are oriented to application in the arm of an anthropomorphous robot. PWI developed a number of torches, oriented to application in single- and multiaxes manipulator of plotter type ( $\mathrm{Fi}^{-}$ gure 5). The advantage of these torches is their integration with filler wire feed mechanism and reduction of wire feeding Bowden to $0.1-0.5 \mathrm{~m}$, that markedly lowers the risk of electrode wire jamming. Moreover, such torches have maximum
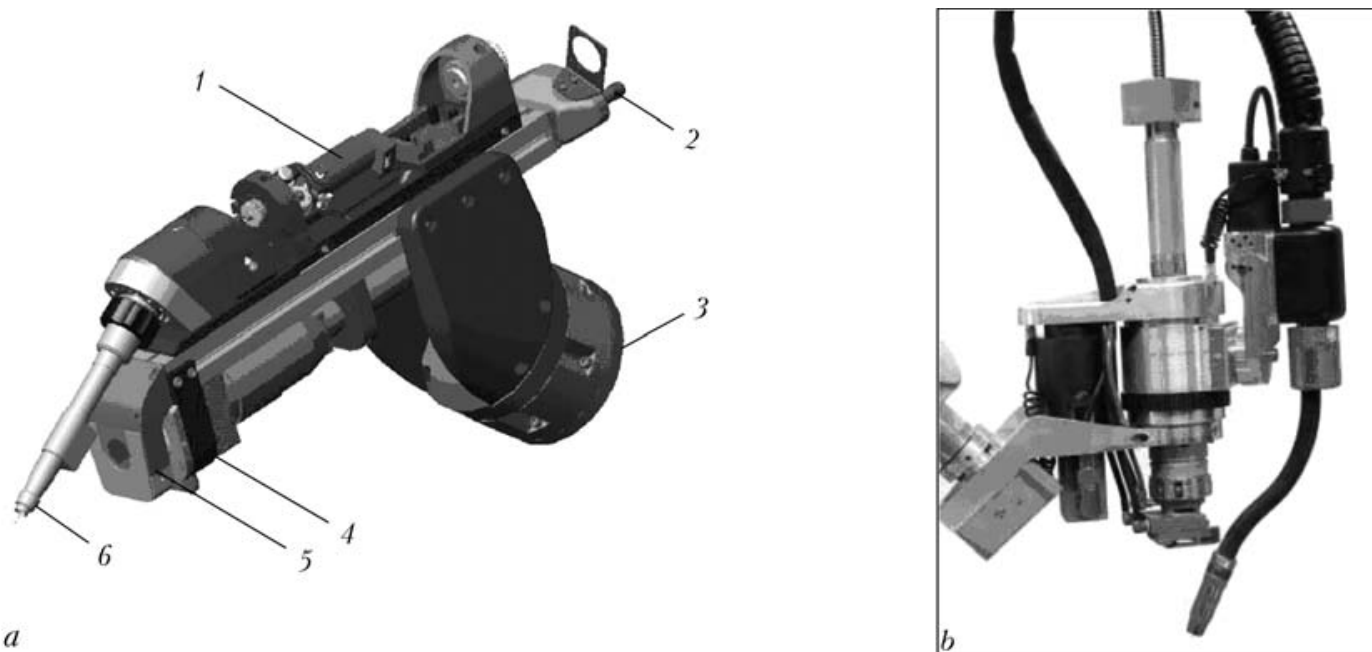

Figure 3. Heads for hybrid laser-arc robotic welding of Fronius $(a)$ and Cloos $(b)$ company [4]: 1 - wire feeder; $2-$ air in-take; 3 - fastening on robot arm; 4 - protective glass; 5 - cross-jet; 6 - water-cooled nozzle

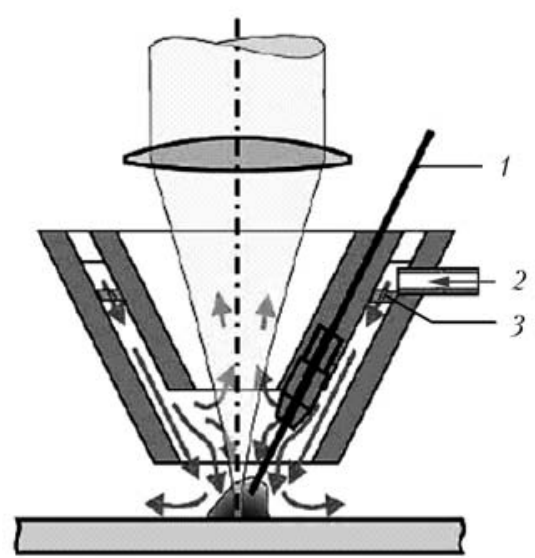

$a$

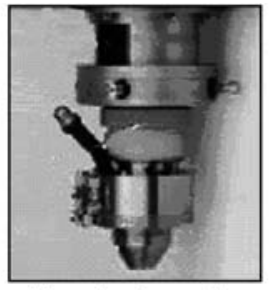

Standard nozzle

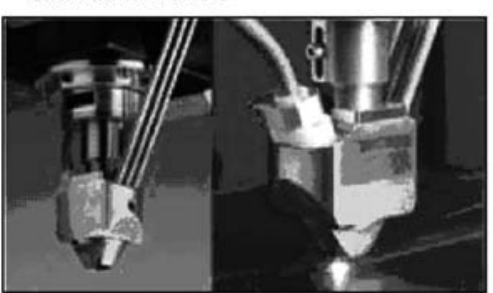

Thin nozzle б

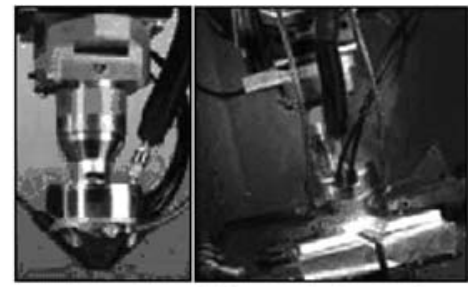

Heavy-duty mode

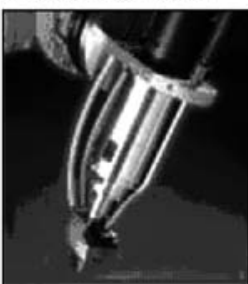

Super thin nozzle

Figure 4. Block-diagram $(a)$ and appearance $(b)$ of heads for hybrid laser-arc welding with integrated nozzle [4]: 1 electrode wire; 2 - auxiliary gas; 3 - diffusion aperture 

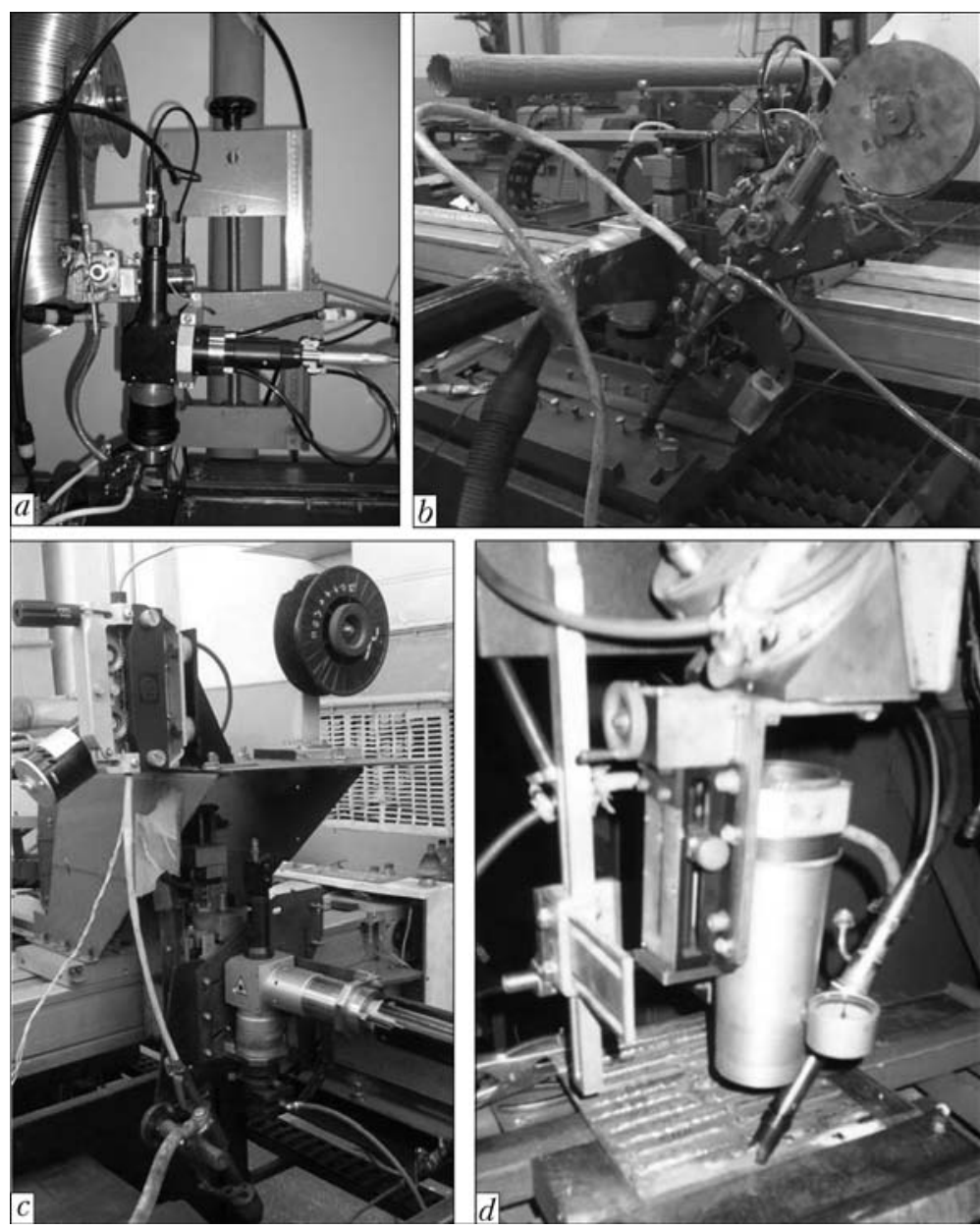

Figure 5. Appearance of heads for hybrid laser-arc welding performed with single- and three-axes manipulator developed at PWI: $a-c-$ for lasers with up to $1.06 \mu \mathrm{m}$ wave length; $d-10.6 \mu \mathrm{m}$

simplified and reliable design, using the simplest standard laser focusing system. Here, it is possible to apply for correction of head displacement path both a TV camera and red laser radiation in the case of diode or Nd:YAG lasers (Figure 5, $a-c)$, and just red radiation in the case of $\mathrm{CO}_{2-}$ laser (Figure 5, $d$ ).

Hybrid welding minimizes the disadvantages of both the laser and MIG welding. According to [3, 4], the main advantages of hybrid laser-arc welding, compared to laser welding, are as follows:

- reduction of capital costs for equipment by 30-40\% compared to laser welding (because of reduction of consumed laser power);

- high welding speeds;

- lowering of edge preparation accuracy;

- controlling weld composition through welding wire selection;

- lowering the risk of quenching structure formation in weld and HAZ metal;

- improvement of process reliability;

- improvement of overall process efficiency, lowering power intensity to $50 \%$.

Achievement of the above advantages, however, requires correct selection of a number of parameters. Let us consider them in keeping with recommendations of $[3,4,6,7]$.

Laser power. Increase of this parameter usually increases the penetration depth. In hybrid laser-arc welding this phenomenon is enhanced due to lowering of reflectivity of metal heated by the arc.

Welding speed. With lowering of welding speed, penetration depth is increased, due to increase of energy applied per a unit of weld length. Moreover, stability of welding wire feeding and melting is improved at lower welding speeds.

Relative position of focused laser radiation and consumable electrode arc. Distance between laser radiation axis and wire tip is one of the most important parameters of optimization of hybrid laser-arc welding. It is usually selected small (up to $2 \mathrm{~mm}$ ). In addition to that, important factors of weld formation are arc torch position in front or at the back in the direction of welding, as well as angle of its inclination.

Focal position. Maximum penetration depth in laser-arc welding is usually achieved at laser beam focusing below the surface of sheets being welded to the depth of $2-4 \mathrm{~mm}$. 
Angle of electrode inclination. Penetration depth rises with increase of the angle of electrode inclination to item surface up to $50^{\circ}$. Gas flow coming out of arc torch deflects the vapour-gas plume formed by laser radiation, and reduces laser energy losses (particularly, at application of $\mathrm{CO}_{2}$-lasers). Therefore, the angle of electrode inclination to item surface usually is equal to about 40 to $50^{\circ}$.

Shielding gas composition. Inert gas (helium, argon, or heir mixtures) is usually applied. At application of $\mathrm{CO}_{2}$-lasers, shielding gas with a higher ionization potential is required to prevent formation of plasma, capable of deflecting or absorbing laser radiation. Therefore, helium is preferable to argon for laser welding. However, helium lightness is a disadvantage, so that it is often used in mixtures with heavier argon. More over, reactive gases such as oxygen and carbon dioxide are added to increase penetration depth.

Modulation of arc component power. Direct current is usually used for powering the welding arc. Pulsed mode is also often used to reduce spatter at preservation of deep penetration. Increase of arc voltage promotes weld widening that reduces the weld form factor (ratio of penetration depth to its width) for the same laser power. Therefore, arc voltage (and wire feed rate) are increased in case of welding loosely fitting edges. Welding current is, usually, directly proportional to welding wire diameter. Welding current increase promotes increase of penetration depth and of weld form factor.

Alignment of edges to be welded. A gap of up to $0.2 \mathrm{~mm}$ is allowable for laser welding. Large gaps lead to such defects as weld sagging or lack-of-fusion. Hybrid laser-arc welding allows joining parts with gaps of up to $1 \mathrm{~mm}$ and more (at high wire feed rates).

Edge preparation. Regular laser welding requires parallel straight edges and narrow gap. For arc welding edge preparation is used (most often, V-shaped). In the case of hybrid laser-arc welding, requirements to edge preparation are lower than for laser welding. Edge preparation is, usually, applied for material thickness greater than 8 to $10 \mathrm{~mm}$.

For better understanding of modern tendencies in development of hybrid laser-MIG welding, let us consider the main stages in evolution of this process according to study [8] performed at PWI.

$1970 \mathrm{~s}$. At the end of $1970 \mathrm{~s}$, a team led by W. Steen at the Imperial College in London made the first attempts at combining laser radiation and electric arc (TIG) for welding metals. This new hybrid laser-arc welding process had a num- ber of advantages, compared to laser and arc processes. It ensured increased process stability, much higher welding speed, deeper penetration and a narrow weld. Nonetheless, this innovation was not immediately accepted by industry [5, 6]. Approximately in 1979-1980 PWI performed the first experiments on laser-arc welding.

1980s. Appearance of reliable and comparatively inexpensive high power lasers allowed introducing laser welding into industry [9]. It was established that its disadvantages can be minimized by combining laser welding with regular arc welding. This allowed increasing process effectiveness, lowering requirements to preparation of edges to be welded, eliminating a number of metallurgical problems and lowering the reflectivity of the metal being welded. Thus, most of the obstacles for laser introduction into welding production were eliminated $[5,6]$.

1990s. Tendencies of industrial realization of laser and hybrid welding, laid down as far back as in 1980s, are manifested. Laser equipment power becomes higher. Development of hybrid laser-arc welding revealed such disadvantages of laser welding, as high cost, complexity of edge preparation and fastening the parts to be welded, as well as a number of metallurgical problems. Investigations of advantages and disadvantages of hybrid laser-arc welding are pursued in all the industrialized countries of the world (USA, Europe and Japan) [10, 11]. Development of these technologies was promoted by industrial need for high-quality welds, produced at a high speed. Such industrial sectors as automotive, shipbuilding and pipeline transportation, became interested in hybrid laser-arc welding.

2000s. Hybrid laser-arc welding equipment has now proved its suitability for many industrial sectors. Integrated hybrid welding heads are being actively developed (for instance, Exial, Fronius, Prima Industry, Permanova Lasersystem) $[6,12]$, various specific production scenarios are simulated and verified. For instance, the issue of joining materials of various type, configuration and thickness by hybrid laser-arc welding is studied. Investigations of the features of this welding process are also carried on, for instance, resonance phenomena occurring at summation of frequency of electrode metal drop transfer with weld pool natural oscillations [13] or influence of pulsed modulation of laser and arc components on the nature of weld formation and their mechanical properties, are studied [14].

Hybrid laser-MIG welding combines the advantages of arc and laser processes, that leads to improvement of welding stability and weld quality and lowering of residual deformations. Industrial advantages include increase of productivity, 
simplification of adjustment procedure and lowering of the cost of one running meter of weld. Nonetheless, this technology still is only at the initial stage of introduction in modern industry sectors. The causes for slow pace of industrial introduction are the high level of investment and process complexity, associated with a large number of its parameters. Despite that, hybrid welding has already been accepted to a certain extent in such industries as automotive and shipbuilding, pipeline transportation, aerospace and aircraft industry, power generation, off-highway and heavy vehicle sectors.

Automotive. Such well-known automotive companies as Volkswagen and Audi are convinced in the superiority of hybrid laser-MIG welding $[12,15]$. Another example of this welding application is Volvo company [16]. Any type of car has a large number of welds, differing by their configuration and applied materials. In many cases, such welding processes as MIG, laser and hybrid laser-MIG welding are combined - depending on weld configuration and requirements to it. MIG welding is applied in the presence of considerable gaps between the edges being welded and with their minimum preparation. $\mathrm{La}^{-}$ ser welding ensures low residual deformations, deep penetration and high speed in the case of accurate fit-up of the parts being welded. And, finally, hybrid welding ensures high welding speeds in combination with relatively broad tolerances. Used for this purpose are 2 to $4 \mathrm{~kW}$ lasers at welding speeds of approximately $4 \mathrm{~m} / \mathrm{min}$ [17]. PWI performed work on development of technologies of laser-arc welding of zincplated steel for automotive applications and thin aluminium alloys for AvtoVAZ company (Toliatti, $\mathrm{RF})$. Technology of reconstructive surfacing of internal combustion engine pistons was also developed [18]. This technology was aimed at both filling the worn grooves of motor transport pistons (from cars up to heavy tractors), and at restoration of railway diesel engine pistons.

Shipbuilding. Hybrid welding process is of great interest for shipbuilding industry all over the world [19, 20]. This process is being actively applied by European and Asian shipyards, whereas in the US shipyards it is introduced rather slowly. Hybrid welding yields a significant saving of time and costs, replacing multipass welding due to realization of deep penetration mode. Here powerful Nd:YAG lasers of up to $6 \mathrm{~kW}$ and $\mathrm{CO}_{2}$-lasers of up to $25 \mathrm{~kW}$ are applied. Examples of shipyards using this technology are Meyer in Germany, Kvaerner in Finland, and Fincantieri in Italy. PWI performed work on development of laser-arc welding technology for ship honeycomb panels from carbon steels 3-
$7 \mathrm{~mm}$ thick for CR\&DI of CM «Prometej» (St.Petersburg, RF).

Pipeline transportation. Investigations of hybrid laser-MAG welding are being performed, aimed at improvement of welding quality and reduction of production costs in manufacturing of large-diameter pipes and mounting of the main pipelines. A process of laser welding of the root weld with subsequent welding up of a narrow gap in one, two or three passes by laser-MAG process was developed for realization under industrial conditions [21]. Stainless steel pipelines are welded without pores, with preservation of austenitic structure and without any significant increase in hardness. Welding speed for these pipelines with 5 to $8 \mathrm{~mm}$ wall thickness is up to $1.2 \mathrm{~m} / \mathrm{min}$ [22]. PWI developed several techniques of welding large-diameter pipes and their position butts [23, 24].

Aerospace and aviation industry. Leading position in aircraft industry is taken by Airbus company, in particular, owing to innovative developments. For several years now this company has applied laser welding process for manufacturing aircraft hull sections, in particular, for Airbus 318 and Airbus 380 models [25, 26]. Recently Airbus has shown interest in hybrid welding technology. This technology also is of great interest for solving aerospace and military tasks when working with titanium alloys [27]. PWI performed a number of studies on welding titanium alloys, aluminium alloys and stainless steels to meet the objectives of Ukrainian aerospace industry [28]. In this work the applicability of both laser and hybrid welding was studied.

Power generation. In equipment applied for power generation it is often necessary to weld plates of more than $15 \mathrm{~mm}$ thickness. In particular, technology of laser welding of such materials has been studied and applied in industry [29], but hybrid welding is gradually attracting ever greater attention for solving this problem, as it is capable of overcoming the disadvantages of laser welding [30]. Here, both laser and hybrid welding are usually applied in multipass mode [31]. In addition to thick plates thin stainless steels are also used in power machine-building, for instance, for manufacturing expansion bellows assemblies. PWI developed technologies and equipment for welding such assemblies for Research-Information Center «Armatom» (Kiev, Ukraine) [32]. Here, preference was given to laser, and not hybrid welding.

Off-highway and heavy vehicles. Laser welding is an already well-established technology in heavy vehicle industry for joining parts from structural steels, and its effectiveness has been proved more than once [33]. Nonetheless, hybrid welding has demonstrated its superiority, com- 
pared to laser welding (for instance, shortening of the time of preparation for welding and finish treatment), and, for this reason, it is gradually becoming ever wider accepted in this industry [34]. Some technological solutions for this industry sector were also developed at PWI [35].

Just several examples of industrial application of hybrid welding have been considered, which is being continuously expanded now. Other possible applications include household appliances, railway transportation, chemical industry (in particular, welding stainless steel tanks and pipes), etc. [36]. Application of laser-arc welding to address the tasks of aluminium structure manufacturing has a special place [37].

\section{Conclusions}

1. Introduction into industry (for instance, in various sectors of transportation, chemical, power and food industry), oriented to partial replacement of laser and arc welding technologies, can be regarded as the main modern tendency of development of hybrid laser$\mathrm{MIG}$ / MAG welding.

2. General tendencies of hybrid welding progress include development of new technologies, focused on welding structures of different chemical composition and geometry, as well as designing new equipment for industrial introduction of the developed technologies.

3 . In connection with a new stage in laser equipment development, which began in the last decade and which is associated with wide industrial introduction of fibre and disc lasers, the issue of giving preference to laser or hybrid welding has become the subject of thorough scientific-technical and economic studies.

1. Steen, W.M., Eboo, M. (1979) Arc augmented laser welding. Metal Constr., 11(7), 332-335.

2. Steen, W.M., William, M. (2003) Laser material processing. 3rd ed. London: Springer-Verlag Ltd.

3. Wouters, M. (2005) Hybrid laser-MIG welding: An investigation of geometrical considerations. Lulea: University of Technology.

4. Kah, P. (2011) Usability of laser-arc hybrid welding processes in industrial applications. Lappeenranta: University of Technology

5. Seyffarth, P., Krivtsun, I.V. (2002) Laser-arc processes and their applications in welding and material treatment. In: Welding and Allied Processes, Vol. 1 London: Taylor and Francis Books.

6. Bagger, C., Olsen, F.O. (2005) Review of laser hybrid welding. J. Laser Appl., 17(1), 2-14.

7. Jokinen, T., Jernstrom, P., Karhu, M. et al. (2003) Optimisation of parameters in hybrid welding of aluminium alloy. Proc. of SPIE, Vol. 4831, 307-312.

8. Shelyagin, V.D., Khaskin, V.Yu. (2002) Tendencies in development of laser-arc welding (Review). The Paton Welding J., 6, 25-28.

9. Ready, J.F. (1997) Industrial applications of lasers London: Acad. Press.

10. Dilthey, U., Wieschemann, A. (2000) Prospects by combining and coupling laser beams and arc welding processes. Welding in the World, 44(3), 37-46.

11. Ishide, T., Tsubota, S., Watanabe, M. et al. (2003) Latest MIG, TIG, arc-YAG laser hybrid welding systems. J. JWS., 72(1), 22-26.
12. Staufer, H. (2005) Laser hybrid welding and laser brazing: State of the art in technology and practice by the examples of the Audi A8 and VW-Phaeton. In: Proc. of 3rd Int. WLT Conf. on Lasers in Manufacturing (Munchen, 2005), 203-208.

13. Shelyagin, V.D., Khaskin, V.Yu., Garashchuk, V.P. et al. (2002) Hybrid $\mathrm{CO}_{2}$-laser and $\mathrm{CO}_{2}$ consumablearc welding. The Paton Welding J., 10, 35-37.

14. Zhernosekov, A.M., Khaskin, V.Yu., Nabok, T.N (2014) Pulsed laser-arc welding of carbon steels. Vost. Evrop. Zhurnal Pered. Tekhnologij, 71(5/1), 12-15.

15. Graf, T., Staufer, H. (2003) Laser-hybrid-welding drives VW improvements. Welding J., 1, 42-48.

16. Lakhti, K.E. (2003) One + one is more than two!!! Svetsaren, 2, 22-24.

17. Staufer, H. (2007) Laser hybrid welding in the automotive industry. Welding J., 10, 36-40.

18. Khaskin, V.Yu. (2009) Application of laser-arc cladding for filling up narrow cavities in aluminium alloy items. The Paton Welding J., 2, 31-34.

19. Merchant, V. (2003) Shipshape laser applications. Industrial Laser Solutions, August. wrew.industriallasers.com

20. Denney, P. (2002) Hybrid laser welding for fabrication of ship structural components. Welding J., 81(Sept.), 58.

21. Staufer, H., Ruehrnoessl, M. (2006) Blechdicken und hohe Schweissgeschwindigkeiten: Laserhybrid- + Tandemschweissen. Der Praktiker, 10, 300-302.

22. Thomy, C., Schilf, M., Seefeld, T. et al. (2003) CO2-Laser-MSG-Hybridschweissen in der Rohrfertigung. Werkstattstechnik on-line, 93(6), 462-466.

23. Shelyagin, V.D., Khaskin, V.Yu., Shitova, L.G. et al. (2005) Multi-pass welding of heavy steel sections using laser radiation. The Paton Welding J., 10, 46-49.

24. Shelyagin, V.D., Khaskin, V.Yu. (2009) Multi-pass welding of pipe steels using laser radiation. Svarshchik, 69(5), 36-38.

25. (2004) Laserstrahlschweissen macht Flugzeuge leichter. Fraunhofer Magazin, 4, 36-37.

26. Mendez, P.F., Eagar, T.W. (2002) New trends in welding in the aeronautic industry. In: Proc. of 2nd Conf. on New Manufacturing Trends (Bilboa, Spain, Nov. 19-20, 2002), 1-10.

27. Shinn, B.W., Farson, D.F., Denney, P.E. (2005) Laser stabilization of arc cathode spots in titanium welding. Sci. and Techn. of Welding \& Joining, 10(4), 475-481.

28. Shelyagin, V.D., Lutsenko, V.I., Khaskin, V.Yu et al. (2012) Development of equipment and technology of automated laser welding of pipe compensating elements for aerospace industry. Nauka $i$ Innovatsii, $8(6), 53-59$.

29. Jokinen, T., Kujanpaa, V. (2003) High power $\mathrm{Nd}$ YAG laser welding in manufacturing of vacuum vessel of fusion reactor. Fusion Eng. and Design, 69(1-4), 349-353.

30. Jokinen, T., Karhu, M., Kujanpaa, V. (2003) Welding of thick austenitic stainless steel using Nd:yttrium-aluminum-garnet laser with filler wire and hybrid process. J. Laser Appl., 15, 220-224.

31. Jokinen, T., Karhu, M., Kujanpaa, V. (2003) Narrow gap hybrid welding of thick stainless steel. In: Proc. of 22nd ICALEO (Jacksonville, FL, USA, 1316 Oct. 2003), 66-75.

32. Lukashenko, A.G., Melnichenko, T.V., Lukashenko, D.A. (2012) Laser welding of sheet stainless steel by modulated radiation. The Paton Welding J., 4, 15-19.

33. Nilsson, K., Engstrom, H., Flingfeldt, J. et al. (2000) High power laser welding of construction steels. Svetsen, 59(1)

34. Hyatt, C.V., Magee, K.H., Porter, J.F. et al. (2001) Laser-assisted gas metal arc welding of 25 -mm-thick HY-plate. Welding J., 80(7), 163-172.

35. Shelvagin, V.D., Krivtsun, I.V., Borisov, Yu.S. et al. (2005) Laser-arc and laser-plasma welding and coating technologies. The Paton Welding J., 8, 44-49.

36. Kah, P Salminen, A Martikainen, J (2010) Laserarc hybrid welding processes (Review). Ibid., 6, 32-40.

37. Khaskin, V.Yu. (2013) Development of laser welding of aluminium alloys at the E.O. Paton Electric Welding Institute (Review). Ibid., 5, 51-55. 